\title{
CONFLITOS DE RELACIONAMENTO ENTRE FRANQUEADOR E FRANQUEADOS: UM ESTUDO EM FRANQUIAS DO RAMO ALIMENTÍCIO SOB A ÓTICA DO FRANQUEADO NA REGIÃO ADMINISTRATIVA DE MARÍLIA (SP)
}

\author{
CONFLICTS OF RELATIONSHIP BETWEEN FRANCHISOR AND \\ FRANCHISEES: A STUDY IN FRANCHISES OF THE FOOD \\ BRANCH FROM THE POINT OF VIEW OF THE FRANCHISEE \\ IN THE ADMINISTRATIVE REGION OF MARÍLIA (SP)
}

\author{
RELACIÓN DE CONFLICTOS ENTRE FRANQUICIADOR Y \\ FRANQUICIADOS: UN ESTUDIO EN FRANQUICIA DE LA \\ INDUSTRIA DE ALIMENTOS BAJO LA ÓPTICA DE \\ FRANQUICIA EN REGIÓN ADMINISTRATIVA MARÍLIA (SP)
}

Clariana Ribeiro Nogueira

Mestre em Administração pela Universidade Estadual de Maringá (UEM), Brasil / Professora na Faculdade da Alta Paulista (FAP) e na Faculdade Reges de Osvaldo Cruz (FEOCRUZ), Brasil

clariana.rib@gmail.com

Ana Elisa Bressan Smith Lourenzani

Pós-doutora na Kansas State University e doutora em Engenharia de Produção pela Universidade Federal de São Carlos, Brasil / Professora assistente da Universidade Estadual Paulista, campus de Tupã, Brasil anaelisa@tupa.unesp.br

\section{Natalia Dadario}

Mestranda do Programa de Pós-graduação em Agronegócio e Desenvolvimento da Universidade Estadual Paulista, campus de Tupã, Brasil / Professora na Faculdade Faccat, lecionando disciplinas para os cursos de Engenharia de Produção e Arquitetura, Brasil nataliadadario@gmail.com

\section{Contextus}

ISSNe 2178-9258

Organização: Comitê Científico Interinstitucional Editor Científico: Carlos Adriano Santos Gomes Avaliação: double blind review pelo SEER/OJS

Recebido em 26/01/2017 Aceito em 05/12/2017 $2^{\mathrm{a}}$ versão aceita em 18/12/2017

\section{RESUMO}

Desde que o franchising surgiu no Brasil, tem sido crescente o interesse de empreendedores por esse formato de negócio. Nas franquias, o franqueado é dono de seu próprio negócio e não empregado do franqueador, e a relação destes é regulada por um contrato com direitos e deveres preestabelecidos. Como existe uma relação de dependência bilateral entre o franqueador e o franqueado, deve-se considerar que o melhor desempenho do negócio depende do relacionamento deles, visando a uma gestão mais eficiente e coordenada. $\mathrm{O}$ tema ainda carece de estudos mais profundos e críticos, principalmente em regiões distantes de grandes centros. O estudo objetivou analisar o relacionamento franqueador-franqueado, mapear pontos críticos e apontar os fatores de conflitos, embasado na teoria da agência.

Palavras-chave: Franquias. Relacionamento franqueador-franqueado. Satisfação do franqueado. Contrato de franquia. Teoria da agência. 


\begin{abstract}
Since franchising began in Brazil, entrepreneurs have taken a growing interest in this business format. In franchising, the franchisee owns his own business, instead of being an employee of the franchisor, and the relationship of both is governed by an agreement in which the rights and duties are predetermined. Since there is a relation of bilateral dependence between franchisor and franchisee, one must consider the best performance of the business as depending on the relationship established between them and as aiming at more efficient and coordinated management. The topic still lacks deeper, more critical studies, especially in regions too far from large centers. This study aims to analyze the franchisor-franchisee relationship, based on agency theory, as well as to map hotspots and indicate factors of conflict that lead to dissatisfaction of the parties.
\end{abstract}

Keywords: Franchises. Franchisor-franchisee relationship. Franchisee satisfaction. Franchise contract. Agency theory.

\title{
RESUMEN
}

Desde que la franquicia se produjo en Brasil, ha habido un creciente interés de los empresarios en este formato de negocio. En la franquicia, el franquiciado es dueño de su propio negocio y no un empleado del franquiciador. Su relación está regulada por un acuerdo con los derechos y obligaciones preestablecidas. Dado que existe una relación de dependencia bilateral entre el franquiciador y el franquiciado, debe tenerse en cuenta que el mejor rendimiento del negocio depende de su relación interpersonal, con miras a una gestión más eficiente y coordinada. La cuestión todavía necesita estudios más profundos y críticos, sobre todo en regiones distantes de los grandes centros. El objetivo del estudio fue analizar la relación franquiciador-franquiciado, mapear puntos críticos y señalar los factores de conflicto, basada en la teoría de la agencia.

Palabras clave: Franquicias. Relación franquiciador-franquiciado. La satisfacción del franquiciado. Contrato de franquicia. teoría de la agencia.

\section{INTRODUÇÃO}

O sistema de franquias, também conhecido pelo termo em inglês franchising, permite a expansão de inúmeras empresas que não teriam tecnologia, estrutura e recursos para um crescimento rápido e sustentável em mercados competitivos e dinâmicos (TOLEDO; PROENÇA, 2004). A franquia se estabelece como importante alternativa de empreendimento devido à característica de menor risco de fracasso (SHANE; ROY, 1996), desde que a franquia seja bem escolhida.

O franchising evoluiu consideravelmente nos últimos anos $\mathrm{e}$ continua em pleno crescimento. Pesquisas da ABF (2015) demonstram que, no Brasil, havia 3.073 empresas franqueadoras com unidades franqueadas em operação, apresentando um faturamento total de mais de R 139 bilhões em 2015. Nesse mesmo ano, o Brasil contava com um total de 138.343 unidades franqueadas, gerando 1.189.785 postos de trabalho diretos.

Apesar do crescimento comprovado do sistema e de suas vantagens, sua efetividade depende, dentre outros fatores, do relacionamento estabelecido entre as duas partes envolvidas: o franqueador proprietário da marca e do know-how do negócio - e o franqueado, que utilizará a marca e os conhecimentos técnicos do franqueador para desenvolver a atividade comercial. Leite (1991) ressalta que o franqueado é independente jurídica e financeiramente do franqueador. Em outras 
palavras, ambos são parceiros, sem vínculo empregatício. Em todo caso, é forte a interdependência: o franchising só existe se houver uma relação mútua de confiança, em que $o$ franqueador oferece sua experiência e suporte operacional, e, em contrapartida, o franqueado oferece seu empenho de proprietário (COMBS; MICHAEL; CASTROGIOVANNI, 2004).

Dada a importância do bom relacionamento entre franqueador $\mathrm{e}$ franqueado para a eficiência e a eficácia da franquia, a presente pesquisa teve como objetivo principal compreender as características de tal relacionamento e analisar seus pontos críticos, além de identificar fatores que acarretam conflitos entre as partes. Serão apontadas variáveis a serem observadas por ambas para evitar futuras divergências na administração do franchising, considerando a natureza do contrato de franquia e apoiando-se na Teoria da Agência.

Por ser um setor em constante crescimento, o sistema tem sido tema de muitos estudos acadêmicos. Este estudo se justifica devido à necessidade existente de alinhar as partes - franqueador $\mathrm{e}$ franqueado - para a continuidade da relação, bem como para o sucesso e a expansão do negócio. No entanto, ainda existe uma escassez de estudos aprofundados e mais críticos abrangendo o assunto em questão, principalmente em relação a regiões distantes de grandes centros, como a Região Administrativa de Marília, localizada no Centro-Oeste paulista.

\section{2}

\section{METODOLOGIA}

Para o desenvolvimento desta pesquisa, foi aplicada uma metodologia de natureza qualitativa. A princípio, para atingir os objetivos, empregou-se a pesquisa de caráter exploratório por envolver um amplo levantamento bibliográfico desenvolvendo e esclarecendo conceitos e ideias (GIL, 1999).

A partir do referencial teórico, foi possível identificar algumas variáveis chave no relacionamento entre franqueador $\mathrm{e}$ franqueado, a coordenação e o conflito, considerando a teoria da agência, os aspectos contratuais e o relacionamento do franqueador e franqueado tendo em vista as fontes de conflito comuns para posterior exame. A partir dessas variáveis, foram elaborados diferentes roteiros de entrevistas do tipo semiestruturada contendo questões fechadas e abertas, nas quais o informante tem a liberdade de discorrer sobre o tema proposto e pode explorar amplamente a questão de forma a coletar dados desejados.

Os roteiros formulados apresentaram um total de 33 questões direcionadas ao franqueador e 52 direcionadas ao franqueado, 
todas referentes ao relacionamento deles. Os roteiros foram divididos em quatro blocos gerais:

a) suporte e assessoria do franqueador ao franqueado, inclusive na seleção e avaliação do ponto para a franquia;

b) relação de confiança e comunicação entre franqueador e franqueado;

c) relacionamento contratual entre as partes;

d) satisfação do franqueado com a gestão da franquia.

Após essa fase, iniciou-se a identificação de franqueadores e franqueados com o perfil desejado, caracterizando a pesquisa como estudo multicaso, uma investigação empírica que examina um fenômeno contemporâneo dentro do seu contexto da vida real (YIN, 2005). Assim, optou-se por duas franquias de alimentos com sede na Região Administrativa de Marília para a aplicação do instrumento de coleta de dados: Franquia A, originária da cidade de Marília, e Franquia B, da cidade de Tupã. Para cada uma delas, entrevistou-se $\mathrm{o}$ franqueador $\mathrm{e}$ selecionou-se um franqueado para aplicação dos roteiros de entrevistas.

A escolha da amostra foi intencional, não probabilística, incluindo "elementos de uma população que são selecionados de maneira não-aleatória” (MCDANIEL; como: acesso e disposição para cooperar com a pesquisa, proximidade da cidade-sede da pesquisa e indicações feitas pelo franqueador.

Por fim, realizaram-se a análise e a interpretação dos dados a fim de estabelecer as relações necessárias entre eles e as questões formuladas com base no referencial teórico, evidenciando, dessa forma, o relacionamento franqueadorfranqueado e outros fatores ligados aos objetivos propostos inicialmente.

\section{TEORIA DA AGÊNCIA}

A franquia empresarial é amplamente difundida no mundo e diversas teorias acadêmicas objetivam explicá-la e compreendê-la. As pesquisas têm tido sua base teórica na Teoria de Escassez de Recursos (Resource Scarcity Theory) e/ou na Teoria da Agência (Agency Theory). A Teoria de Escassez dos Recursos considera o franchising como um mecanismo adequado para prover capital para expansão do negócio devido às condições de escassez de recursos do mercado. Já a Teoria da Agência vê o sistema de franquia como um mecanismo para melhorar o alinhamento de incentivos entre a empresa e as suas unidades. As duas teorias não são contraditórias, mas sim complementares. Uma firma pode atrair recursos e alinhar incentivos ao mesmo tempo

GATES, 2008, p. 372). Baseou-se em critérios 
(COMBS; MICHAEL; CASTROGIOVANNI, 2004).

A teoria da agência é uma das mais efetivas para discutir a relação entre franqueador e franqueado, semelhante à relação principal e agente. A teoria da agência busca analisar as relações entre os participantes de um sistema, onde propriedade e controle são designados a pessoas distintas, o que pode resultar em conflitos de interesse entre as partes (JENSEN; MECKLING, 1976). Logo, tal base teórica aborda o franchising com base em custos de monitoramento, assimetria de informações e alinhamento de interesses entre agente e principal, respectivamente franqueado $\mathrm{e}$ franqueador.

O franqueado é agente do franqueador, uma vez que o representa e distribui seus produtos, serviços e marcas, mas não necessariamente busca $\mathrm{o}$ melhor para $\mathrm{o}$ franqueador (principal), podendo, por exemplo, adquirir produtos de um fornecedor não autorizado pelo principal para burlar o pagamento de royalties (porcentagem sobre as vendas) (LAVIERI, 2008).

Conforme aponta Merlo (2000), a teoria da agência emerge do problema de assimetria de informação existente numa relação, quando se tem de um lado o proprietário de capital e de outro o gestor. Buscando entender a relação entre franqueador e franquia nesses termos, a assimetria informacional entre o principal e o agente é fonte de potenciais problemas de agência. Esse aspecto mostra a relevância de analisar o grau de comunicação entre franqueador e franqueado, pois este possui melhores informações que aquele a respeito das operações locais. Dessa forma, se as informações são distribuídas de forma assimétrica entre aqueles que tomam decisões (franquia) e aqueles que, teoricamente, deveriam se beneficiar dessas decisões (franqueador), então as decisões da franquia podem não estar de acordo com os interesses do franqueador (GREENWALD; STIGLITZ, 1990).

O problema surge da necessidade de que as ações do agente (gestor) estejam de acordo com os interesses do principal. Cientes do problema de seleção adversa, o alinhamento de interesses pode ser, pelo menos parcialmente, evitado por meio do estabelecimento de critérios de escolha para seleção dos franqueados e de mecanismos de enforcement previstos em contratos (MERLO, 2000).

$\mathrm{Se}$ ambas as partes procuram maximizar seus ganhos, é de se esperar que o agente não atue, necessariamente, no melhor interesse do principal. Além disso, em algumas situações, o principal gastará recursos adicionais (custos de monitoramento) para garantir que o agente não tome certas atitudes prejudiciais àquele ou, na ocorrência delas, 
para garantir alguma compensação. Geralmente é impossível assegurar, sem custo adicional, que o agente tome a decisão ótima do ponto de vista do principal (JENSEN; MECKLING, 1976).

O franchising, por meio de um esquema de remuneração baseado em uma taxa fixa e outra variável, transfere o lucro excedente para o franqueado, que, por esse motivo, passa a ter interesse na rentabilidade do negócio. Ao alinhar os interesses de franqueado e franqueador, o contrato de franquia reduz a necessidade de controle via monitoramento, do primeiro pelo segundo (LAFONTAINE, 1992).

De acordo com Rubin (1978), franqueados não reduzirão os esforços para melhorarem a gestão da empresa, porque sua renda é amarrada aos seus esforços. Em contrapartida, em negócios convencionais, os gerentes podem fugir de determinadas responsabilidades porque não se apropriam dos resultados. Dessa forma, segundo Lafontaine (2002), o contrato de franquia proporciona ao franqueado mais incentivos do que têm os gerentes de negócios convencionais.

Lafontaine (1992) aponta também o problema de moral hazard (risco moral) e double-sided moral hazard (duplo risco moral). O risco moral surge quando o agente e o principal têm objetivos individuais diferentes e o principal não pode identificar facilmente se as ações do agente são conduzidas com a finalidade de atingir o objetivo do principal ou são ações em seu interesse próprio. Conforme Bitti (2003), o risco moral denota o comportamento indesejado de agentes uma vez que o esforço contratado não pode ser plenamente monitorado. O conceito inclui aspectos de informação assimétrica, comportamento oportunista de indivíduos e baixa efetividade de monitoramento, por exemplo.

Quanto ao duplo risco moral, Lafontaine (1992) afirma que, se por um lado, o franqueador tem uma marca, uma imagem e um formato de negócio a zelar, por outro, o franqueado assume o risco financeiro do investimento. O oportunismo por parte do franqueado pode significar perda da imagem da marca - muitas vezes o principal ativo do franqueador. Heinze (2005) explica a diferença desse modelo para o anterior afirmando que, além do problema de risco moral pelo lado do franqueado, há também risco moral por parte do franqueador. Dessa forma, um contrato ótimo é o que incentiva as duas partes.

\section{ASPECTOS CONTRATUAIS}

No Brasil, segundo Carvalho e outros (2006), as empresas começaram a denominar suas operações de franquia em meados da década de 1980. Os precursores, tais como 
Yázigi International e Bob's, trabalhavam com esse formato de negócio ainda sem o conhecimento do conceito, sendo muito recente sua disseminação.

As redes passaram a adotar oficialmente o sistema apenas na década de 1990, quando se consolida a legislação brasileira específica. A Lei do Franchising ( $\mathrm{N}^{\circ}$ 8.955 de dezembro de 1994) foi promulgada para regular os contratos do sistema, definindo responsabilidades, direitos e deveres de cada uma das partes. A definição legal de franquia empresarial é a seguinte:

Franquia empresarial é o sistema pelo qual o franqueador cede ao franqueado o direito de uso de marca ou patente, associado ao direito de distribuição exclusiva ou semi-exclusiva de produtos ou serviços e, eventualmente, também ao direito de uso de tecnologia de implantação e administração de negócio ou sistema operacional desenvolvido ou detido pelo franqueador, mediante remuneração direta ou indireta, sem que, no entanto, fique caracterizado vínculo empregatício (Lei $\mathrm{n}^{\circ} 8955$ de 15 de dezembro de 1994).

De acordo com a Lei 8.955/94 e com o código de autorregulamentação do franchising, o franqueador é a pessoa jurídica detentora dos direitos de uso e exploração de um conceito de negócio e das marcas comerciais que o identificam. O franqueado, por sua vez, é a pessoa física ou jurídica a quem se outorga a permissão de uso e exploração do conceito de negócio e demais direitos concernentes a um determinado sistema de franquia. Essa relação pode ser melhor compreendida com a Figura 1 de Beschel (2001). 
Figura 1 - Relação entre franqueador e franqueado em um contrato de franchising

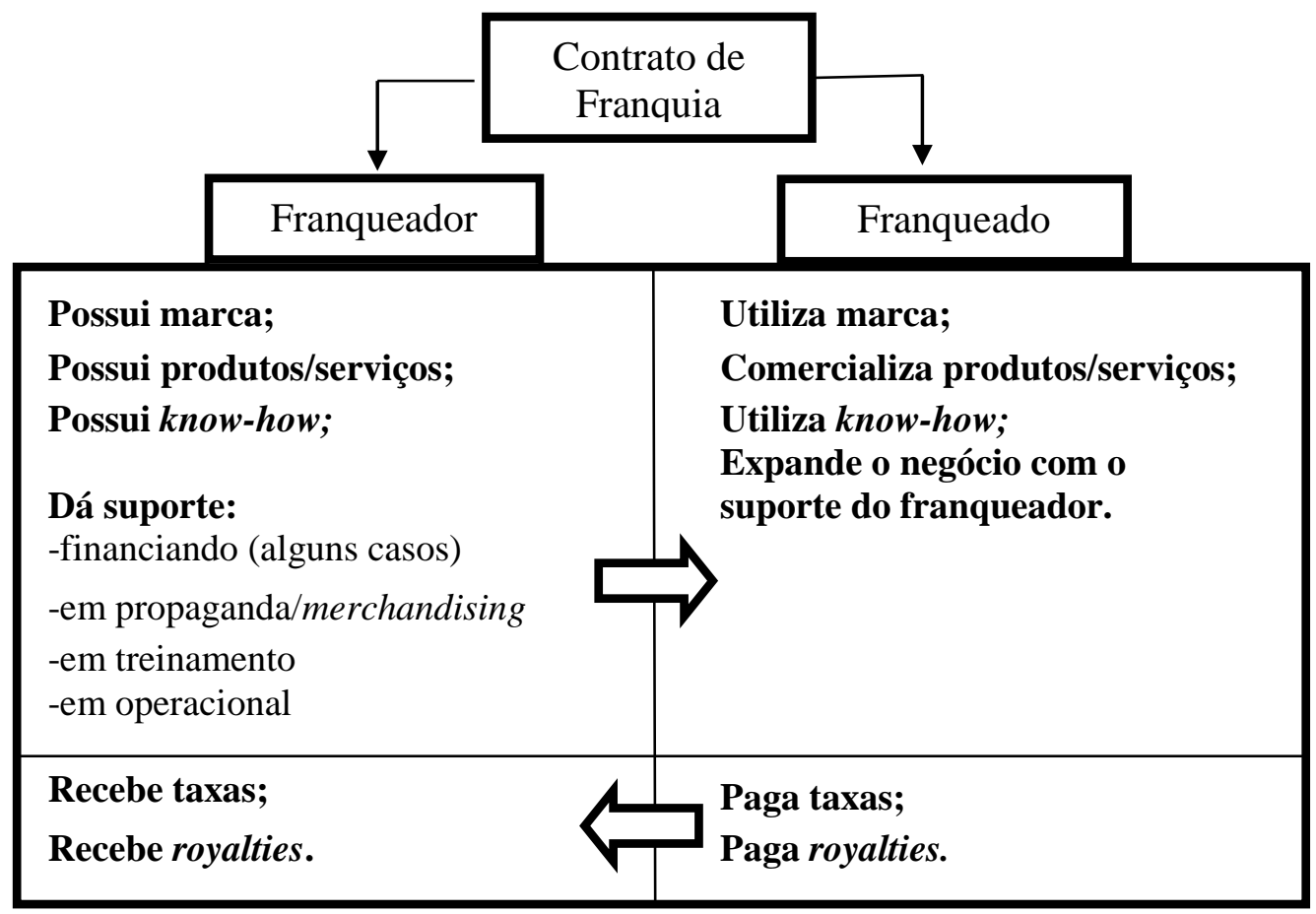

Fonte: BESCHEL (2001)

Donoso (2010) esclarece que o contrato de franquia pode ser pactuado com algumas cláusulas livres pelas partes. Geralmente, porém, costumam ser obrigações padrões dos franqueados:

a) pagamento de royalties, normalmente em períodos mensais e de acordo com o faturamento;

b) pagamento de uma taxa de adesão, que pode ou não incluir os serviços de organização empresarial;

c) exclusividade de comercialização dos produtos do franqueador;

d) obedecer às instruções do franqueador sobre preço de venda aos consumidores; e) obedecer aos padrões estéticos do estabelecimento, determinado pelo franqueador.

As obrigações do franqueador, de acordo com a Associação Brasileira de Franchising são:

a) apoio técnico para a localização e a viabilidade econômica do ponto comercial;

b) assistência para o aluguel ou compra de equipamentos;

c) projeto e execução das instalações;

d) treinamento técnico e gerencial contínuo;

e) participação cooperada e prestação de assessoria de marketing; 
f) criação de procedimentos padronizados de operações e contabilidade;

g) centralização de compras e instruções para controle de estoques;

h) orientação financeira e análise de balanços.

A importância da utilização de contratos é justificada a partir de Heinze (2005) que afirma que cada indivíduo tem seus próprios interesses e que raramente são alinhados igualmente com os interesses dos outros indivíduos ou grupos aos quais pertence, sendo que o mesmo ocorre entre empresas e organizações. Cada lado ou agente tem seu interesse próprio, que pode conflitar com o interesse do outro. Se as organizações precisam agir entre si para um estado mutuamente benéfico, é celebrado um contrato.

O relacionamento entre o franqueador e seu franqueado não se esgota no cumprimento do contrato, vai muito além, envolvendo contatos interpessoais diários focados na operacionalização e acompanhamento do negócio do franqueado, resolução de problemas comuns e, de maneira intangível, o compartilhamento de valores, objetivos, aspectos psicológicos e sociais que permeiam a interação das partes (MAURO, 2004).

\section{RELACIONAMENTO FRANQUEADOR-FRANQUEADO}

No caso específico do franchising, somente estratégias voltadas para o ambiente externo à empresa podem não ser suficientes para compreender o desempenho alcançado por toda a rede ou por seus franqueados individualmente. $\mathrm{O}$ melhor ou pior relacionamento entre franqueador $\mathrm{e}$ franqueado enquanto resultado de uma estratégia do franqueador voltada para seu ambiente interno pode ser fator relevante para o sucesso ou fracasso do empreendimento (COHEN, SILVA, 2000).

A partir de uma coordenação no sistema de franquia fica evidente que o franqueador deva buscar congruência entre as suas metas e as do franqueado, direcionando seus esforços para a preservação e valorização da marca, ativo em comum a ambos. O franqueador se depara com a realidade da existência de diferenças nas estruturas de custos entre franqueador e franqueado, de desejo de autonomia do franqueado, de existência de risco moral e de possibilidade de comportamento oportunista (FÁVERO, LUPPE, VANCE, 2008).

Franqueador e franqueado compartilham do mesmo objetivo: o sucesso da franquia. Embora o interesse seja comum a ambos, pode haver muita complexidade neste relacionamento devido aos papéis de cada um 
e pontos distintos de vista. De acordo com Sherman (1993), um grau de tensão é intrínseco ao relacionamento entre franqueador e franqueado, isto faz parte da relação estabelecida.

O franqueador investiu tempo, esforço e capital para projetar e desenvolver o seu sistema, incluindo os padrões de qualidade a serem seguidos. Por outro lado, o franqueado geralmente deseja ser o seu próprio patrão e tende a resistir a imposições. Merlo (2000) explica que muitas vezes a adesão a um sistema já desenvolvido irá impor ao franqueado uma série de controles externos e restringir sua liberdade de condução do negócio, sendo diferente de ser o empreendedor do seu próprio negócio.

De maneira geral, do ponto de vista do franqueado, Plá (2001) descreve os problemas mais comuns que podem levar a um desentendimento com $\mathrm{o}$ franqueador, tais como: falta de assistência, má utilização da verba de publicidade, conflitos de território, não acompanhamento de padrões, entre outros. Ainda observando o lado dos franqueados insatisfeitos, algumas das reclamações mais frequentes referem-se ao apoio inadequado e despreparo administrativo por parte do franqueador, à cobrança de taxas e royalties exorbitantes, à submissão quase total do franqueado às normas ou decisões do franqueador e ao fornecimento de dados irrealistas quanto ao capital investido, custos e tempo de retorno do investimento.

Já pelo lado dos franqueadores, as queixas mais comuns referem-se à falta de preparo, de estrutura e de seriedade dos franqueados

(BERNARD, 1993;

SCHWARTZ, 1994). Diz-se que em franquias os conflitos começam quando ambas as partes precisam tirar o contrato da gaveta, reexaminá-lo e discutir o não cumprimento das regras e padrões preestabelecidos (PLÁ, 2001).

As fontes de conflitos e de disputas mais comuns entre $\mathrm{o}$ franqueador $\mathrm{e} \mathrm{o}$ franqueado são as seguintes, definidas por Sherman (1993):

- Recrutamento e seleção do franqueado: fase fundamental para garantir que o franqueado é um membro com perfil adequado ao sistema e de que o sistema é apropriado ao franqueado.

- Seleção de ponto comercial e direitos territoriais: em geral, o franqueado é responsável pela seleção do ponto comercial e o franqueador aprova ou não a indicação. Franqueadores que desenvolveram critérios bem definidos para a seleção do ponto tiveram poucos problemas com seus franqueados.

- Pagamento de royalties e fornecimento de informações: o correto pagamento de royalties e a respectiva prestação de contas 
podem ser motivos de rompimento de contrato por justa causa, por parte do franqueador.

- Administração do fundo de propaganda: o fundo tem a finalidade de criar uma verba a ser aplicada em ações promocionais, a qual deve ser administrada separadamente das demais despesas incorridas pelo franqueador. Alguns franqueadores utilizam os recursos do fundo quando atravessam dificuldades financeiras, o que pode causar rompimento de contrato.

- Supervisão e suporte: Os conflitos surgem quando os franqueados alegam que o franqueador deixou de prestar os serviços combinados previamente.

- Controle de qualidade: o sucesso de um sistema franqueado está na proteção da imagem da marca e manutenção da alta qualidade dos produtos e serviços. Os franqueadores devem certificar-se de que os franqueados comercializam apenas produtos e serviços aprovados e com o padrão de qualidade da rede.

- Tratamento desigual: franqueados esperam que o sistema seja uniforme, e qualquer arbitrariedade ou desigualdade no tratamento conduz a ressentimento e hostilidade por parte dos outros franqueados, particularmente quando um tratamento diferenciado é dado às lojas próprias.

- Crescimento rápido: franqueadores com ênfase predominantemente em vendas ao invés de suporte, em quantidade ao invés de qualidade, em lucro ao invés de satisfação de seus franqueados, apresentam alta probabilidade de fracasso.

O Quadro 1 apresenta um resumo dos conceitos dos autores referentes às fontes de conflitos mais comuns entre franqueadores $\mathrm{e}$ franqueados. 
Quadro 1 - Fontes de conflitos entre franqueadores e franqueados

\begin{tabular}{|c|c|}
\hline Autores & Fontes de Conflitos \\
\hline Plá (2001) & $\begin{array}{l}\text { - Falta de assistência; } \\
\text { - Má utilização da verba de publicidade; } \\
\text { - Conflitos de território; } \\
\text { - Não acompanhamento de padrões; } \\
\text { - Apoio inadequado; } \\
\text { - Falta de preparo administrativo por parte do franqueador; } \\
\text { - Cobrança de taxas e royalties exorbitantes; } \\
\text { - Submissão do franqueado às normas ou decisões do franqueador; } \\
\text { - Fornecimento de dados irrealistas quanto ao capital investido; } \\
\text { - Custos e tempo de retorno do investimento. }\end{array}$ \\
\hline $\begin{array}{l}\text { Bernard (1993), } \\
\text { Schwartz (1994) }\end{array}$ & $\begin{array}{l}\text { - Falta de preparo e de estrutura; } \\
\text { - Falta de seriedade dos franqueados. }\end{array}$ \\
\hline Nathan (2003) & $\begin{array}{l}\text { - Falta de alinhamento entre as expectativas de ambas as partes; } \\
\text { - Confusão em relação aos papéis de atuação das partes; } \\
\text { - Existência de diferenças significativas na percepção das duas partes; } \\
\text { - Estado emocional do franqueado diferente no relacionamento; } \\
\text { - Falta de consulta ao franqueado para a tomada de decisão; } \\
\text { - Baixa rentabilidade do negócio. }\end{array}$ \\
\hline Sherman (1993) & $\begin{array}{l}\text { - Recrutamento e seleção do franqueado; } \\
\text { - Seleção de ponto comercial; } \\
\text { - Pagamento de royalties e fornecimento de informações; } \\
\text { - Administração do fundo de propaganda; } \\
\text { - Supervisão e suporte; } \\
\text { - Controle de qualidade; } \\
\text { - Tratamento desigual do franqueador com os franqueados; } \\
\text { - Crescimento rápido. }\end{array}$ \\
\hline
\end{tabular}

Fonte: elaborada pelas autoras.

\section{RESULTADOS E DISCUSSÃO}

\subsection{Apresentação dos casos}

A Região Administrativa de Marília situa-se no Centro-Oeste do estado de São Paulo e ocupa um território de $18.458 \mathrm{~km}^{2}$, que corresponde a $7,91 \%$ do território paulista. É composta por 51 municípios distribuídos em quatro regiões de governo: Assis; Marília; Ourinhos; e Tupã (SEADE, 2017). Os casos selecionados são de franquias oriundas dessa região, uma de Marília e outra de Tupã, com seus respectivos franqueados 
localizados em Bauru e em Marília. No entanto, ambas as franquias já possuem franqueados em outras regiões de São Paulo e do Brasil, sendo redes estabelecidas a nível nacional. Visando resguardar a identidade e quaisquer informações de ambas as franquias, as mesmas serão designadas por Franquia A e Franquia B.

\section{Franquia A}

A primeira loja surgiu em setembro de 1990 na cidade de Marília interior de São Paulo. Em junho de 2005 a empresa passa por uma reestruturação com nova direção, 8 meses depois em fevereiro de 2006 é inaugurada a segunda unidade na cidade de Presidente Prudente, interior de São Paulo, iniciando assim a implantação do sistema de franquias pela rede.

A franquia conta atualmente com 75 unidades franqueadas espalhadas em todo o país. Cada loja tem, em média, 15 funcionários e estão localizadas na sua maioria em shoppings, mas também há lojas em grandes supermercados. Recebeu o Selo de Excelência em Franchising por mais de uma vez.

Para a análise do relacionamento estabelecido entre as partes, entrevistou-se o franqueador localizado em Marília-SP e selecionou-se um franqueado localizado em Bauru-SP. Este franqueado é um dos primeiros da rede, atuando como franqueado há mais de dez anos. O mesmo já foi franqueado de outra unidade em AraraquaraSP, no entanto, atualmente é franqueado de duas unidades, uma no Bauru Shopping e outra no supermercado de Bauru-SP.

\section{Franquia B}

A franquia foi fundada em 1990 em Tupã-SP e em 1993, a Franquia B dava seus primeiros passos rumo à franquia, como já era planejado desde o início do negócio. Já alcançou o número de mais de 100 unidades franqueadas espalhadas por todo o Brasil. Possui uma história de reconhecimento, prêmios, títulos e conquistas bastante consolidada (como por exemplo o Selo de Excelência da ABF por diversos anos consecutivos, prêmio de Franqueador do Ano, título de Destaque Franchising, entre outros).

Para a coleta dos dados, entrevistou-se a unidade franqueada localizada no município de Marília-SP analisando o seu relacionamento com o franqueador na unidade de Tupã-SP. O franqueado atua na franquia há cerca de dezessete anos, pois já tinha contato com o franqueador e acompanhou o desenvolvimento e crescimento do negócio. 


\subsection{Suporte e assessoria do franqueador ao franqueado}

No quesito "suporte e assessoria do franqueador ao franqueado" foi analisada a percepção dos fraqueados com relação ao suporte e apoio que é oferecido pelo franqueador no início e ao longo da operação da franquia. A assistência que o franqueado recebe do franqueador é iniciada, geralmente, antes mesmo da nova unidade começar a operar. Por parte da Franquia A, o franqueador auxiliou na seleção e avaliação do ponto com profissionais capacitados que pesquisaram o melhor ponto comercial, sendo que o próprio franqueador já havia escolhido um ponto atrativo para abertura da franquia, antes do convite ao franqueado. A franquia possui uma equipe de profissionais para avaliar cada ponto de venda potencial nas principais cidades para redução de riscos para as lojas.

A classificação da qualidade da assessoria oferecida para o ponto comercial compreendeu-se entre "insuficiente", "pouco satisfatória", "satisfatória", "muito satisfatória" e "plenamente satisfatória". De acordo com este franqueado a assessoria oferecida para o ponto comercial pode ser considerada como "muito satisfatória".

Com relação à Franquia $\mathrm{B}$, também houve um estudo e avaliação do melhor local para a franquia com a participação do franqueador, além de apoio no projeto arquitetônico e auxílio na escolha dos equipamentos e funcionários. A assessoria para a escolha do local foi classificada como "satisfatória" pelo franqueado da rede de cachaçarias.

Com o treinamento ofertado pelo franqueador, o franqueado torna-se apto a iniciar o negócio de imediato, pois adquire a experiência e o conhecimento de trabalho que o franqueador acumulou durante anos. Dessa forma, com relação ao treinamento préoperacional oferecido pelo franqueador, a Franquia A informou que houve testes realizados na franquia máster por oito finais de semana para aprender todas as receitas praticadas pela rede e o gerenciamento da parte administrativa, ou seja, oferece treinamento ao franqueado e a toda equipe de funcionários por 30 dias, antes e durante a inauguração das lojas. Além disso, o franqueador se encarregou de recrutar e selecionar os funcionários para iniciar na franquia.

O franqueado da Franquia B, por sua vez, afirmou que o treinamento préoperacional é de uma semana no qual é realizado um test-drive, ou seja, o potencial franqueado fica na operação e assim, realizase uma análise deste. Afirmou que também houve treinamento inicial dos funcionários durante trinta dias feito in loco já trabalhando na própria franquia máster. 
Foi possível aos franqueados classificar o treinamento pré-operacional dos franqueadores variando na mesma escala. Por parte da Franquia A este treinamento foi classificado como "muito satisfatório" pelo franqueado, enquanto que o franqueado da Franquia B considerou-o como "satisfatório".

Questionou-se aos franqueados como são os treinamentos oferecidos durante a gestão da franquia e segundo o entrevistado da Franquia A, o diretor de franqueados treina os novos funcionários na franquia máster para melhor conhecimento do negócio, não havendo outros treinamentos durante a gestão da franquia, além deste no início do negócio. Já na Franquia B, além do treinamento inicial, há o contínuo realizado periodicamente o que atualiza constantemente os procedimentos da franquia. Alguns treinamentos principais da Franquia B são: administração e gestão do negócio; atendimento ao cliente, gestão da qualidade, gestão de estoques, informática/Internet/Extranet/Intranet, planejamento

seleção/treinamento/motivação da equipe de vendas.

A supervisão e a auditoria das unidades franqueadas caracterizam o sistema de franquias, contribuem para o aperfeiçoamento do trabalho, além de aproximar franqueador e franqueado. $\mathrm{Na}$ franquia A, a supervisão e auditoria das unidades franqueadas são realizadas de acordo com o andamento da loja, quando há necessidade. Segundo o entrevistado há o telefone (linha 0800) que serve como um canal entre os consumidores e a franquia, assim, caso o cliente seja mal atendido ou tenha alguma sugestão ou reclamação referente à franquia, informa à franquia máster que realiza a supervisão desta unidade. De acordo com o franqueado pode ser considerada "satisfatória" a qualidade da supervisão e auditoria, porém estas não são feitas com muita regularidade.

O franqueado da Franquia B considera muito importante a realização de auditoria e supervisão em seu negócio e afirma que é realizada de forma rígida e no mínimo a cada três meses todas as unidades franqueadas recebem visitas de uma equipe de supervisores regionais que avaliam se o padrão da rede segue conforme o estabelecido. Este item também é considerado como "satisfatório" para o franqueado.

Foi questionado de que forma é realizado o suporte e monitoramento das unidades franqueadas. $\mathrm{Na}$ Franquia $\mathrm{A}$ o suporte é realizado on-line para todas as unidades que recebem informações principalmente em questões como atualização e troca do cardápio, mudança de banner e de promoção na franquia. Classificou-se como "muito satisfatório" este suporte. A Franquia B afirmou que a estrutura é satisfatória que a franquia máster está disponível para suporte 
sempre que surgir qualquer dificuldade na unidade.

Para a verificação de desempenho atingido pelo franqueado, questionou-se referente aos indicadores utilizados pelo franqueador para analisar o desempenho das franquias. A Franquia A informou que há relatórios de vendas e a partir deste relatório é realizado um ranking de todas as lojas e os franqueados podem acompanhar seu desempenho comparando com as demais unidades e com os meses anteriores. Além disso, há o feedback recebido pelas ligações dos consumidores que elogiam ou reclamam do serviço a partir do telefone (linha 0800), o canal de comunicação direto com a franquia.

No caso da Franquia B, o desempenho é verificado por meio de diversas ferramentas. São estas: relatórios de avaliação, faturamento mensal do negócio e até mesmo o boca-aboca, que contribui para a ciência do desempenho da unidade franqueada. $\mathrm{O}$ franqueado afirmou ainda que uma ferramenta importante é o cliente oculto que consiste em um avaliador que se passa por um cliente para consumir na franquia. $\mathrm{O}$ mesmo analisa $\mathrm{e}$ mede a qualidade do atendimento sem que o franqueado saiba.

O sistema de franquia é caracterizado pelo pagamento de diversas taxas como royalties e fundo de propaganda, que podem, muitas vezes, preocupar potenciais franqueados. De acordo com Magalhães (2013), os royalties são como um investimento que os franqueados fazem coletivamente para sustentar a operação da empresa franqueadora, visando a constante melhoria dos padrões, serviços e produtos da rede.

No que tange às taxas cobradas na franquia, ambos os franqueados pagam aos franqueadores as taxas já citadas, sendo que a Franquia A ainda paga taxa de propaganda. Segundo o franqueado, os produtos são divulgados na mídia por meio de revistas, outdoors e televisão. Estas podem ser consideradas pelo franqueado da Franquia A como "muito justas" considerando a divulgação da marca e ações promocionais realizadas e ao apoio recebido do franqueador. Já estas taxas para o franqueado da Franquia B são consideras como “justas”. Ambos franqueados se encontram satisfeitos com os valores das taxas pagas, pois consideram o custo baixo se comparado com o apoio recebido e o retorno financeiro observado por parte de tais ações.

Para facilitar a comparação entre o Suporte e assessoria do franqueador ao franqueado, a seguir é apresentado o Quadro 2 com tais informações. 
Quadro 2 - Assistência e suporte dos franqueadores para os franqueados

\begin{tabular}{|lcc|}
\hline \multicolumn{1}{|c}{ Suporte recebido do franqueador } & \multicolumn{2}{c|}{ Franqueado } \\
\hline & Franquia A & Franquia B \\
Estudo de Viabilidade & $\mathrm{X}$ & $\mathrm{X}$ \\
Treinamento Inicial & $\mathrm{X}$ & $\mathrm{X}$ \\
Treinamento Contínuo & & $\mathrm{X}$ \\
Execução de Publicidade & $\mathrm{X}$ & $\mathrm{X}$ \\
Supervisão Periódica & $\mathrm{X}$ & $\mathrm{X}$ \\
Fornecimento de manuais & & $\mathrm{X}$ \\
Assistência para comprar equipamentos & $\mathrm{X}$ & $\mathrm{X}$ \\
Investimento em tecnologias & $\mathrm{X}$ & \\
Orientação financeira e análise de balanços & & \\
\hline
\end{tabular}

Fonte: elaborada pelas autoras.

O franqueado da Franquia B afirmou que ainda há por parte do franqueador suporte no projeto financeiro; mercadológico; organizacional e projeto de operação. Além disso, os franqueados da rede contam com apoio jurídico e apoio para financiamento, sendo que no fornecimento de manuais está incluso a orientação sobre o método de trabalho desta franquia.

Por sua vez, o franqueado da Franquia A informou que o franqueador oferece controle de qualidade visando uniformidade nos padrões de operação; campanhas nacionais de marketing e orientação para marketing local; rede nacional de distribuição de matéria prima e possui também um sistema computadorizado de vendas que são ligados diretamente a central que fica na cidade de São Paulo.

\subsection{Relação de confiança e comunicação entre franqueador-franqueado}

Referente à relação de confiança e comunicação existente entre as partes, de acordo com ambos os franqueados há um sistema eficiente nesta relação. $\mathrm{O}$ franqueado da Franquia B mencionou que há um portal específico que facilita muito esta comunicação de forma on-line. Além disso, ambos os franqueados estão cientes da missão e visão da empresa.

Indagou-se se o franqueador oferece aos franqueados da rede encontros nacionais ou regionais e ainda se há um conselho consultivo de franqueados e a frequência destes eventos e a resposta foi positiva para ambas as redes. Por parte da Franquia A, o conselho consultivo é realizado nas próprias reuniões periódicas entre os franqueados e o 
franqueador e os encontros regionais são realizados entre quatro e cinco vezes por ano. A Franquia B oferece conselho consultivo aos franqueados a cada dois meses. Além disto, há encontros regionais e nacionais que acontecem de três a cinco vezes ao ano, variando a frequência de um ano para o outro. Vale acrescentar que foi ressaltada a relevância do conselho consultivo na tomada de decisões estratégicas de forma mais eficiente nas franquias.

Com relação ao tratamento oferecido aos franqueados, a Franquia A afirma que o tratamento não é igualitário entre os demais franqueados da rede. Isto ocorre devido ao elevado poder aquisitivo do franqueador que se relaciona de forma mais próxima e atenciosa apenas aos franqueados com padrão similar, não se preocupando da mesma forma com franquias de menor porte, segundo o franqueado. Examinou-se que esta pode ser uma fonte de conflito relevante a ser destacada. Diferentemente do que ocorre na Franquia B em que há sistemas padronizados na forma do franqueador se relacionar com os demais franqueados.

Quando questionados sobre a segurança transmitida nas orientações passadas pelo franqueador, o franqueado da Franquia B afirmou haver "muita segurança", enquanto que a Franquia A considera que estas informações são "suficientes". Ambos os franqueados responderam da mesma maneira respectivamente aos demais quesitos: relação de confiança, relação de parceria e transparência de informações referentes à franquia. Nota-se que os franqueados se sentem como parceiros, de fato, estando satisfeitos com as orientações passadas, confiança, parceria e transparência das informações, embora o franqueado A mostrase mais satisfeito.

Analisou-se se o franqueador consulta os franqueados para implementação de mudanças na empresa que afetem o negócio. Segundo o franqueado da Franquia B esta consulta é frequente, já o franqueado da Franquia A afirma que ocorre sempre que a mudança interfira na franquia. Questionou-se ainda se os franqueadores são abertos a sugestões no negócio e ambos os franqueados responderam que sim. Na Franquia $\mathrm{B}$ as sugestões ocorriam principalmente no início do negócio que estruturaram principalmente o cardápio e outras questões relacionadas à qualidade que é associada a esta franquia. Pelo lado da Franquia A, as sugestões são predominantemente com relação às promoções realizadas.

A fim de saber quais os pontos que mais interferem negativamente entre os citados durante a realização da pesquisa, questionou-se aos franqueados quais destes afetam mais no relacionamento estabelecido com o respectivo franqueador. $\mathrm{O}$ franqueado da Franquia B afirmou que não existem 
questões que levem a divergências, pois sempre procuram um acordo, o que resolve a situação prontamente, sem acumular para depois. No entanto, a Franquia A apontou o tratamento desigual por parte do franqueador. Segundo este franqueado, o franqueador mostra-se pouco presente no suporte a algumas franquias por ser dono de muitos outros negócios. Algumas vezes há dificuldade de acesso ao franqueador em determinadas ocasiões em que os franqueados necessitam dele.

Entre os pontos mais divergentes entre as partes, novamente $\mathrm{o}$ franqueador da Franquia B afirmou não ocorrer, uma vez que da parte dele, estes atritos são evitados, sendo assim, conjuntamente procuram a melhor decisão. Com relação à Franquia A, o franqueado cita que as divergências são corriqueiras referentes ao lançamento de produtos promocionais, pois o franqueador, em alguns casos, realiza promoções que não são viáveis para os franqueados e que não compensam financeiramente para a franquia, inclusive este fato já trouxe prejuízo para a loja, uma vez que o cliente opta pelas promoções e deixam de consumir produtos com maior margem. Porém, a principal dificuldade encontrada no relacionamento com o franqueador é o nível diferente no tratamento entre os franqueados em que tal franqueado sugeriria que a opinião de todos os franqueados fosse ouvida. Estes aspectos ressaltados pelo franqueado A evidenciam a assimetria de informações que ocorre entre agente e principal, a qual pode levar a prejuízos financeiros para a franquia $\mathrm{A}$, além de um desgaste no relacionamento estabelecido entre os interessados.

\subsection{Relacionamento contratual entre as partes}

No estabelecimento de franquias, é necessária uma considerável disposição de negociação até a assinatura do contrato definitivo. Assim, questionou-se aos franqueados se houve uma análise do contrato de franquia antes de aceitá-lo e a resposta foi positiva para ambos os franqueados. Quanto ao período de tempo entre o interesse na franquia e a consolidação do negócio, a Franquia A informou que foi de um ano, próximo à Franquia $\mathrm{B}$ que foi onze meses.

Os franqueadores ofereceram a Circular de Oferta de Franquia (COF) no início do negócio e com relação às informações contidas, ambos os franqueados consideram que as informações transmitidas pelo franqueador foram "satisfatórias", seguindo a escala já apresentada. Além disso, ambos os franqueados afirmam que os papéis de atuação de ambas as partes com seus respectivos direitos e obrigações mútuos estão claramente definidos e que ambos sempre cumpriram o que foi estabelecido previamente no contrato. 
Referente aos franqueadores, os franqueados também concordam em afirmar que os franqueados sempre respeitam as regras e padrões que foram estabelecidos previamente no contrato, sendo que nunca foi necessário retirar o contrato da gaveta e reexaminá-lo. No entanto, o franqueado da Franquia $A$ afirmou que o franqueador descumpriu com uma responsabilidade relevante para a franquia em um momento que estavam com um problema relacionado ao recebimento de matéria-prima e todos os franqueados solicitaram que houvesse um aumento no preço do cardápio, porém o franqueador atrasou este aumento e o cardápio ficou com preço desatualizado gerando prejuízos para os franqueados. Embora esta situação isolada tenha ocorrido o franqueador corrigiu buscou compensá-los posteriormente.

\subsection{Satisfação do franqueado com a gestão da franquia}

A partir de uma nota variando entre 0 e 10, solicitou-se aos franqueados que demonstrassem seu grau de satisfação com relação a variáveis na gestão que se encontra na Tabela 1 .

Tabela 1 - Satisfação do franqueado com a gestão da franquia

\begin{tabular}{|c|c|c|}
\hline \multirow[t]{2}{*}{ Satisfação do franqueado } & \multicolumn{2}{|c|}{ Franqueado } \\
\hline & Franquia A & Franquia B \\
\hline $\begin{array}{l}\text { 1. Suporte administrativo e operacional prestado } \\
\text { pelo franqueador desde o início do negócio }\end{array}$ & 08 & 08 \\
\hline 2. Decisão de investir com este franqueador & 08 & 10 \\
\hline $\begin{array}{l}\text { 3. Comprometimento e profissionalismo com o } \\
\text { negócio por parte do franqueador }\end{array}$ & 09 & 10 \\
\hline 4. Relacionamento estabelecido com o franqueador & 06 & 10 \\
\hline $\begin{array}{l}\text { 5. Comunicação e transmissão de informações entre } \\
\text { ambas as partes }\end{array}$ & 10 & 10 \\
\hline $\begin{array}{l}\text { 6. Confiança que as obrigações e os deveres do } \\
\text { franqueador serão cumpridos }\end{array}$ & 08 & 10 \\
\hline $\begin{array}{l}\text { 7. Grau de dependência do franqueado com relação } \\
\text { ao franqueador }\end{array}$ & 10 & 10 \\
\hline 8. Rentabilidade e retorno financeiro do negócio & 10 & 08 \\
\hline 9. Cumprimento das regras do contrato & 10 & 10 \\
\hline Média da satisfação dos franqueados & 8,7 & 9,5 \\
\hline
\end{tabular}

Fonte: elaborada pelas autoras. 
Pode-se perceber a partir deste quadro que o franqueado da Franquia B está muito satisfeito com a maior parte das variáveis relevantes na gestão da franquia. Entretanto, o suporte administrativo e operacional no início do negócio e a rentabilidade e retorno financeiro da franquia são os itens que este franqueado apresenta um nível de satisfação ligeiramente menor, o que não $\mathrm{o}$ fez se arrepender de investir com este franqueador, pois associou uma nota 10 a esta ação.

A Franquia A, por sua vez, mostra-se satisfeita, porém percebe-se que o item "relacionamento estabelecido com o franqueador" foi o que recebeu a menor nota. Outros pontos de notas intermediárias atribuídas são o suporte administrativo e operacional no início do negócio, a decisão de investir com este franqueador e a confiança que as obrigações e os deveres do franqueador serem cumpridos. Os demais itens variaram entre 09 e 10. No entanto, este franqueado mostra-se mais satisfeito com a rentabilidade e retorno financeiro do negócio em comparação a resposta da Franquia B.

A partir da média realizada da satisfação dos franqueados com os itens estudados, tem-se que a satisfação do franqueado da rede B está elevada, enquanto que a satisfação da Franquia A obteve uma média inferior. Apesar de satisfeito com o negócio, há alguns pontos de divergência que devem ser examinados a fim de que esta relação possa melhorar e não traga conflitos futuros que possam prejudicar a franquia.

Por fim, considerando os pontos expostos e discutidos, os franqueados no final da entrevista foram convidados a classificar o seu nível de satisfação com o negócio de acordo com o que disseram em relação à assessoria que é prestada e que já foi prestada, ao pagamento de taxas, a respeito do retorno dos investimentos, e os problemas e conflitos enfrentados no decorrer do período do contrato de franchising.

Assim, os franqueados puderam expor seu nível de satisfação com a franquia de uma forma em geral e em uma escala variando de "insatisfeito", "pouco satisfeito", "satisfeito", "muito satisfeito" e "plenamente satisfeito", ambos os franqueados consideram "muito satisfeitos" com a gestão da franquia. Utilizando a mesma escala apresentada, questionou-se sobre o nível de satisfação com o franqueador do negócio, o franqueado da franquia A considera-se "satisfeito", apesar dos pontos negativos apontados e o da Franquia B considera-se "muito satisfeito" com o franqueador. 


\section{CONSIDERAÇÕES FINAIS}

O presente estudo compreendeu uma análise do relacionamento estabelecido entre franqueador e franqueado observando a perspectiva do franqueado. A partir dos dados levantados, foi possível identificar características importantes do relacionamento estabelecido entre as partes demonstrando não apenas o grau de satisfação dos franqueados com relação aos franqueadores, mas também os principais pontos que ambos devem trabalhar a fim de aperfeiçoar a rede.

De forma geral, os franqueados mostram-se satisfeitos ou muito satisfeitos tanto com a gestão da franquia quanto com seus parceiros, apesar da satisfação do franqueado $B$ ser mais notável comparativamente à do franqueado $\mathrm{A}$, devido a aspectos perceptíveis do principal e do agente. Os franqueados consideram ainda que as taxas pagas aos franqueadores são justas ou muito justas tendo em vista o apoio recebido por parte dos franqueadores e que os aspectos contratuais acordados previamente são cumpridos.

Contudo, foi possível realizar a identificação de pontos de divergência em questões cotidianas e rotineiras da rede que se entende como divergências necessárias para o aperfeiçoamento da franquia. Conforme estudos anteriores, nota-se a presença de um ponto de conflito que está entre as fontes de conflito e de disputas mais comuns: a não uniformidade de tratamento dos franqueados, destacada pelo franqueado A. Esse ponto pode, inclusive, acentuar problemas de comunicação que, por sua vez, podem acarretar maiores assimetrias de informações entre as partes, sendo necessário um alinhamento dos interesses das partes que reflita melhor comunicação, conforme aponta a teoria da agência.

Infere-se das entrevistas que algumas dificuldades encontradas nas franquias podem conduzir à insatisfação do franqueado: suporte administrativo e operacional no início do negócio; rentabilidade e retorno financeiro da franquia; falha de comunicação e transmissão de informações entre as partes; relacionamento estabelecido com o franqueador; confiança que as obrigações e os deveres do franqueador serão cumpridos. Tais apontamentos destacados devem ser levados em consideração e aperfeiçoados buscando um melhor gerenciamento da franquia $\mathrm{e}$ alinhamento entre as partes que favoreçam o sucesso do negócio a fim de que a longo prazo tais problemas não se tornem mais limitantes ao relacionamento de franqueados e franqueadores.

Dado que este estudo multicaso se limitou a entrevistar duas franquias do ramo alimentício - um franqueado e um franqueador de cada -, as conclusões deste estudo se aplicam, basicamente, às empresas 
entrevistadas. $\mathrm{O}$ estudo propicia um estímulo ao desenvolvimento do tema com outros estudos empíricos, recomendando-se que outras franquias sejam pesquisadas e que sejam incluídos mais franqueados de uma mesma rede de franquia a fim de alcançar uma maior abrangência para os resultados constatados. O que se nota da literatura referente às franquias é que este assunto ainda é muito abordado apenas evidenciando aspectos conceituais e vantagens e desvantagens de franquias. Assim, estudos deste tipo conseguem se aprofundar na rotina das franquias compreendendo questões estratégicas e pontos relevantes referentes ao relacionamento estabelecido pelas partes envolvidas, uma vez que a parceria deve ser o preponderante no relacionamento das partes, embora possuam papéis e objetivos individuais distintos. 


\section{REFERÊNCIAS BIBLIOGRÁFICAS}

ASSOCIAÇÃO BRASILEIRA DE FRANCHISING. 2015. Disponível em: <http://www2.portaldofranchising.com.br/central/Content/UploadedFiles/Arquivos/desempenhofranchising-novo-2015.pdf >. Acesso em: 11 jan. 2017.

AZEVEDO, P.F.; SILVA, V.L.S.; SILVA, A.G.A. Franquias de alimentos. In: NEVES, M.F.; CASTRO, L.T. Marketing e Estratégia em Agronegócios e Alimentos. São Paulo: Atlas, 2003.

BERNARD, D. A. Franchising estratégico: como obter alavancagens e sinergias por meio da taxa inicial e dos royalties. Revista de Administração de Empresas (FGV), São Paulo, 1993.

BESHEL, B. An Introduction to Franchising: Instructor's Guide. The IFA Educational Foundation, 2001. Disponível em: 〈http://www.franchise.org>. Acesso em: 12 abr. 2012.

BITTI, E. J. S. Efeitos da dispersão geográfica de lojas em redes de franquia do Brasil. Dissertação de Pós-graduação. Fundação Instituto Capixaba de Pesquisas em Contabilidade, Economia e Finanças (FUCAPE). Vitória, 2007.

BRASIL. Lei $n^{o} 8955$ de 15 de dezembro de 1994. Dispõe sobre o contrato de franquia empresarial (franchising) e dá outras providências.

CARVALHO, N.; MELO, L. Q.; ROCHA, C. T. ; TAVARES, H. F. ; RODRIGUES, L. F. C. Um estudo sobre o processo de franquias no Brasil como ser um franquiado. In: V Congresso de Administração da Unifenas- Gestão estratégica e empreendedorismo, 2006, Alfenas. V Congresso de Administração da Unifenas - Gestão estratégica e empreendedorismo. Alfenas, 2006.

COHEN, M.; SILVA, J. O impacto das decisões estratégicas no desempenho dos franqueados em fast-food: o papel do relacionamento franqueador-franqueado. Dissertação de Mestrado. Pontifica Universidade Católica do Rio de Janeiro. Brasil, 2000.

COMBS, J. G., MICHAEL, S. C., CASTROGIOVANNI, G. J. Franchising: A Review and Avenues to Greater Theoretical Diversity. Journal of Management, 30(6), (2004), p. 907-931.

FÁVERO, L. P. L.; LUPPE, M. R.; VANCE, P. S. Franquia Empresarial: Um Estudo das Características do Relacionamento Entre Franqueadores e Franqueados no Brasil. Revista de Administração, São Paulo, v. 43, n.1, p. 59-71, jan/fev/mar. 2008. 
GIL, A. C. Métodos e Técnicas de Pesquisa Social. 5. Ed. São Paulo: Atlas, 1999.

GREENWALD, B. C.; STIGLITZ, J. E. Asymmetric information and the new theory of the firm: financial constraints and risk behavior. American Economic Review, v. 80, n. 2, p. 160-165, May 1990.

HEINZE, F. G. Determinantes de esquemas de pagamentos em contratos de franquia. Dissertação de Mestrado. Getúlio Vargas. São Paulo, 2005.

JENSEN, M. C.; MECKLING, W. H. Theory of the Firm: Managerial Behavior, Agency Costs and Ownership Structure. Journal of Financial Economics, Universidade de Rochester, v. 3, n.4, p. 305-360. 1976.

LAFONTAINE, F. Agency Theory and Franchising: Some Empirical Results. RAND Journal of Economics, v. 23, n. 2, (1992), p. 263-283.

LAVIERI, C. A. Sistemas de avaliação de desempenho aplicados em redes de franquias. Dissertação de Mestrado. Faculdade de Economia, Administração e Contabilidade da Universidade de São Paulo. São Paulo, 2008.

LEITE, R. C. Franchising: Na Criação de Novos Negócios. 2. Ed. São Paulo: Atlas, 1991.

MAGALHÃES, P. N. Contrato de franquia: origem desenvolvimento e atual situação no sistema jurídico brasileiro. Disponível em: <www.franca.unesp.br/PedroNavesMagalhaes.pdf>. Acesso em: 27 out. 2013.

MAURO, P. C. Guia do franqueador: Como Crescer Através do Franchising. São Paulo: Editora Nobel, 1994.

MCDANIEL, Carl D.; Gates, Roger. Pesquisa de marketing. São Paulo: Cengage Learning, 2008.

MERLO; E. M. O desempenho do setor de franquias no Brasil. Tese de Doutorado em Administração. Universidade de São Paulo - Faculdade de Economia, Administração e Contabilidade. 2000.

PLÁ, D. Tudo sobre franchising. Rio de Janeiro: Editora SENAC, 2001.

RIBAS, J. A. S. Confidencial: Por Dentro de uma Franquia. Caxias do Sul - RS: Editora Maneco, 2006. 
RUBIN, P. H. The theory of the firm and the structure of the franchise contract. Journal of Law and Economics. V. 21, 1978. p. 223-233.

SCHWARTZ, J. C. Franchising: o que é, como funciona. Brasília: SEBRAE, 1994.

SECRETARIA DE ECONOMIA E PLANEJAMENTO. Região Administrativa de Marília. 2017. Disponível em: <http://www.planejamento.sp.gov.br/index.php?id=50\&idd=156>. Acesso em: 11 jan. 2017.

SHANE, S. A.; Hoy, F. Franchising: A gateway to cooperative entrepreneurship. Journal of Business Venturing, 11: 325-327, 1996.

SHERMAN, A. J. The Franchising Handbook. New York: AMACOM, 1993.

SILVA, V. L. S.; AZEVEDO, P. F. Formas Plurais no Franchising de Alimentos: Evidências de Estudos de Caso na França e no Brasil. RAC. Revista de Administração Contemporânea, v. 11, p. 129-152, 2007.

SISTEMA ESTADUAL DE ANÁLSE DE DADOS. Região Administrativa de Marília. 2012. Disponível em: <http://www.seade.gov.br/produtos/iprs/analises/RAMarilia.pdf>. Acesso em: 10 out. 2013.

TOLEDO, G. L.; PROENÇA, M. C. A. Relacionamento entre franqueador e franqueado como fator crítico para o sucesso da franquia. Caderno de Pesquisas em Administração (USP), São Paulo, v. 1, p. 33-43, 2005.

YIN, R. K. Estudo de Caso: Planejamento e Métodos. 3. Ed. Porto Alegre: Bookman, 2005. 